\title{
PERCEPÇÃO DE PROFESSORES DE FÍSICA EM QUESTÕES ENVOLVENDO RELAÇÕES CTS
}

\author{
Rodrigo Bastos Cunha ${ }^{1}$ \\ Universidade Estadual de Campinas \\ http://orcid.org/0000-0003-3679-1062
}

\begin{abstract}
RESUMO:
Após décadas de contribuições de pesquisas sobre a abordagem das relações entre ciência, tecnologia e sociedade no ensino de ciências naturais, alguns estudos de caso apontam dificuldades encontradas por professores de física para inserir em suas aulas debates sobre questões sociais. Este artigo apresenta um recorte de uma pesquisa de percepção sobre ensino de ciências naturais, iniciada em 2020, para mostrar as opiniões de professores de física, em formação e em exercício, sobre questões envolvendo as relações CTS. Foi aplicado um questionário pela internet, através do Google Docs, com perguntas sobre o foco do ensino de ciências naturais, o que deve ser privilegiado, o quanto o entrevistado concorda com determinadas afirmações envolvendo as relações CTS e qual a relevância o entrevistado atribui a quatro temas do cânone da ciência e a cinco temas socioambientais, em uma escala de zero a dez. Foram coletadas 950 respostas no total, das quais 215 são de professores de física, em exercício e em formação. Os resultados apontam que as questões envolvendo as relações CTS estão bastante consolidadas na percepção dos entrevistados e que as opiniões dos professores de física, no geral, são bem próximas das opiniões dos demais atores da comunidade de ensino de ciências naturais. Um dado que merece destaque é a altíssima relevância atribuída pelos estudantes de licenciatura em física a dois temas socioambientais, um envolvendo preservação ambiental e outro envolvendo aquecimento global. Tanto os professores de física quanto os demais atores do universo geral de entrevistados atribuíram maior relevância a quatro temas socioambientais em comparação com a relevância atribuída aos temas do cânone da ciência. Esses dados apontam para o potencial de temas socioambientais que podem ser usados como temas geradores e ponto de partida para o ensino de conceitos científicos, tanto da física quanto das demais disciplinas.
\end{abstract}

Palavras-chave: Pesquisa de percepção. Abordagem CTS. Ensino de física.

\section{ABSTRACT: \\ PERCEPTION OF PHYSICS TEACHERS IN MATTERS INVOLVING STS RELATIONS}

After decades of research contributions on the approach of the relationship between science, technology and society in the teaching of natural sciences, some case studies point out difficulties encountered by physics teachers in inserting debates on social issues in their classes. This article presents an excerpt from a survey of perception on teaching natural sciences, started in 2020, to show the opinions of physics teachers, in training and practice, on issues involving STS relations. A questionnaire was applied over the internet, through Google Docs, with questions about the focus of natural sciences teaching, what should be privileged, how much the interviewee agrees with certain statements involving STS relations and what relevance the interviewee attributes to four themes in the canon of science and to five socio-environmental themes, on a scale from zero to ten. A total of 950 responses were collected, of which 215 are from physics teachers, in practice and training. The results show that the issues involving STS relations are well consolidated in the perception of the interviewees and that the opinion of physics teachers, in general, are very close to the opinions of the other actors in the natural sciences teaching

1 Doutor em Linguistica Aplicada. Professor do Programa de Pós Graduação em Divulgação Científica e Cultural (UNICAMP). Pesquisador do Laboratório de Estudos Avançados em Jornalismo. E-mail: rbcunha@unicamp.br 
community. A datum that deserves to be highlighted is the very high relevance attributed by the students of degree in physics to two socio-environmental themes, one involving environmental preservation and the other involving global warming. Both physics teachers and the other actors in the general universe of respondents attributed greater relevance to four socio-environmental themes compared to the relevance attributed to the themes of the canon of science. These data point to the potential of socio-environmental themes that can be used as generating themes and a starting point for teaching scientific concepts, both in physics and in other disciplines.

Keywords: Perception research. STS approach. Physics teaching.

\section{RESUMEN:}

\section{PERCEPCIÓN DE LOS PROFESORES DE FÍSICA EN ASUNTOS ENVUELTOS EN LAS RELACIONES CTS}

Después de décadas de contribuciones de investigación sobre cómo abordar la relación entre ciencia, tecnología y sociedad en la enseñanza de las ciencias naturales, algunos estudios de caso señalan las dificultades que encuentran los profesores de física para insertar debates sobre cuestiones sociales en sus clases. Este artículo presenta un extracto de una encuesta de percepción sobre la enseñanza de las ciencias naturales, iniciada en 2020, para mostrar las opiniones de los profesores de física, en formación y en ejercicio, sobre asuntos envueltos en las relaciones CTS. Se aplicó un cuestionario en Internet, a través de Google Docs, con preguntas sobre el enfoque de la enseñanza de las ciencias naturales, qué debe ser privilegiado, en qué medida el entrevistado está de acuerdo con ciertas afirmaciones que involucran relaciones CTS y qué relevancia atribuye el entrevistado a cuatro temas del canon de la ciencia y cinco temas socioambientales, en una escala de cero a diez. Se recogieron un total de 950 respuestas, de las cuales 215 son de profesores de física, en ejercicio y en formación. Los resultados muestran que los temas que involucran las relaciones CTS están bien consolidados en la percepción de los entrevistados y que las opiniones de los profesores de física, en general, son muy cercanas a las opiniones de los demás actores de la comunidad de la enseñanza de las ciencias naturales. Un dato que merece ser destacado es la altísima relevancia que los estudiantes de licenciatura en física atribuyen a dos temas socioambientales, uno que involucra preservación ambiental y otro que involucra calentamiento global. Tanto los profesores de física como los otros actores del universo general de encuestados atribuyeron mayor relevancia a cuatro temas socioambientales frente a la relevancia atribuida a los temas del canon de la ciencia. Estos datos apuntan al potencial de los temas socioambientales que se pueden utilizar como temas generadores y un punto de partida para la enseñanza de conceptos científicos, tanto en la física como en otras disciplinas.

Palabras clave: Encuesta de percepción. Enfoque CTS. Enseñanza de la física.

\section{Introdução}

Após praticamente meio século de debates e pesquisas sobre as relações entre ciência, tecnologia e sociedade, sobretudo após a primeira conferência mundial da Organização das Nações Unidas sobre meio ambiente, em 1972, já é bastante robusta a produção acadêmica sobre propostas de ensino com abordagem CTS. No entanto, alguns autores, como Silva e Carvalho (2009), relatam estudos de caso em que professores de física em formação apontam dificuldades para incorporar essas propostas nas aulas do ensino médio. Segundo esses autores, "alguns licenciandos indicam que a formação que receberam na universidade acaba tendo uma influência decisiva em relação àquilo que compreendem por ensino de Física" (SILVA \& CARVALHO, 2009, p. 141). 
Refletindo sobre a formação de professores de física, Belançon (2017) defende que não seria preciso criar uma nova disciplina CTS nos cursos de licenciatura para se discutir a ciência e seus desdobramentos sociais, pois a raiz do problema estaria na estrutura dos cursos de física, que precisam ser atualizados. Ele faz os seguintes questionamentos:

Se a física é um agente transformador de tantas faces da humanidade, por que o ensino de física deve ficar restrito às leis e à resolução de exercícios? Ou melhor ainda, as listas de exercícios deveriam ser repletas de cálculos vazios? O aluno defender sua posição a favor ou contra a energia nuclear numa dissertação não é um exercício de física? [...] se centenas de milhares de estudantes de exatas, sobretudo de engenharia vão estudar física IV todos os anos, a física não deveria ser apresentada a eles embutida com as questões tecnológicas e políticas de nossa sociedade no século XXI? (BELANÇON,

2017, p. 2)

Além das eventuais dificuldades de inserção de questões sociais em aulas de física, que alguns professores justificam pelo "receio de uma aprendizagem menos exigente e com um menor número de conceitos científicos" (SILVA \& CARVALHO, 2009, p. 137), também há uma grande diversidade de propostas para que as abordagens CTS cheguem efetivamente em sala de aula. Strieder e Kawamura (2008, p. 2) se identificam com aquelas que têm "o objetivo de contribuir para que a sociedade passe a compreender a atividade científico-tecnológica e, além disso, seja capaz de intervir em situações relacionadas à mesma". Esses autores defendem uma associação da abordagem CTS com os ideais de ensino transformador propostos por Paulo Freire, partindo de temas geradores que possibilitem debates com os alunos voltados para a transformação da sua realidade e tornem o ensino mais dialógico e menos centrado exclusivamente no professor.

Dentre as várias pesquisas no âmbito da pós-graduação que buscam apresentar propostas de aplicação de abordagens CTS na prática do ensino, muitas escolhem trabalhar com questões socioambientais como temas geradores. O tema da energia nuclear, apontado por Belançon (2017), é um exemplo bastante explorado por pesquisadores da área como tema gerador, a partir do qual são abordados conteúdos de física no ensino médio. Campos (2017), por exemplo, aplicou uma proposta em uma escola pública de Angra dos Reis (RJ), cidade que abriga as únicas usinas nucleares existentes no Brasil. A abordagem envolveu, além da usina nuclear, as hidrelétricas, termoelétricas, eólicas, solares e usinas de ondas, tratando dos benefícios e riscos de cada modo de geração de energia.

Segundo Campos (2017), o objetivo dessa proposta é levar os alunos a refletirem sobre as implicações sociais, ambientais, econômicas, éticas e políticas das diferentes formas de geração de energia elétrica. Os impactos socioambientais e econômicos da produção de energia, 
nessa proposta, são o ponto de partida para o ensino de conceitos de energia mecânica, energia cinética, energia nuclear, energia térmica, potência e radioatividade, entre outros.

Neste artigo, iremos apresentar os resultados de uma pesquisa de percepção sobre ensino de ciências naturais que teve como objetivo verificar o quanto os pressupostos do ensino CTS foram incorporados por professores em exercício e em formação, após décadas de esforços ligados a mudanças curriculares, inovação nos materiais didáticos e, sobretudo, na reestruturação da formação de professores. Trata-se de um levantamento com um público amplo, envolvendo estudantes de licenciatura em ciências, biologia, física e química, professores dessas disciplinas nos ensinos fundamental e médio, e professores do ensino superior nas áreas da educação, biologia, física e química que pesquisam o ensino de ciências. Faremos, aqui, um recorte das opiniões dos professores de física, em formação e em exercício, para compará-las às opiniões do universo geral de entrevistados.

Nas próximas seções, será descrita a metodologia adotada na pesquisa e, em seguida, será apresentado o perfil dos professores de física entrevistados, por gênero, faixa de idade e nível de escolaridade. Por fim, apresenta-se as opiniões dos professores de física em questões envolvendo as relações entre ciência, tecnologia e sociedade.

\section{Metodologia}

A pesquisa de percepção sobre ensino de ciências naturais, cujo recorte parcial envolvendo professores de física será apresentado aqui, teve como público alvo estudantes de licenciatura em ciências, biologia, física e química, professores de ciências do ensino fundamental, professores de biologia, física e química do ensino médio e professores das áreas de educação, biologia, física e química do ensino superior. Foi aplicado um questionário pela internet, através de formulário gerado no Google Docs, em que os respondentes não se identificavam.

O questionário tinha a seguinte estrutura: cinco perguntas sobre o perfil do entrevistado (gênero, faixa etária, nível de escolaridade, nível em que leciona e disciplina que leciona ou pretende lecionar); uma pergunta sobre qual deve ser o foco do ensino de ciências (a natureza da ciência, questões sociais ou ambas as coisas); uma pergunta sobre o que o ensino de ciências deve privilegiar (a formação de novos cientistas, a formação para tomadas de decisões como cidadão ou ambas as coisas); três perguntas do tipo Escala de Likert, para ver o grau de concordância ou discordância em relação a determinadas afirmações sobre as relações entre ciência, tecnologia e sociedade; e, por fim, uma lista com nove temas em ordem aleatória, dos quais quatro são temas do cânone da ciência e cinco são temas socioambientais, para os entrevistados atribuírem 
a relevância de cada um deles em uma escala de zero (0) a dez (10), em que zero é nada relevante e dez é extremamente relevante.

O questionário ficou disponível e aberto a respostas de 14 de setembro a 21 de dezembro de 2020. Foram enviados, por email, convites para as coordenações de graduação em licenciatura em ciências, biologia, física e química repassarem a seus estudantes; para escolas com segundo ciclo do ensino fundamental e escolas com ensino médio repassarem a seus professores de ciências, biologia, física e química; e para pesquisadores que participaram dos últimos encontros acadêmicos de ensino de biologia, física e química e de encontros acadêmicos sobre ensino de ciências.

No total, foram coletadas 950 respostas, das quais 215 são de professores de física, em exercício e em formação, cujas opiniões são o foco deste artigo.

\section{Perfil dos professores de física entrevistados}

A pesquisa de percepção sobre ensino de ciências naturais teve como público geral estudantes de licenciaturas em ciências, biologia, física e química, professores dessas disciplinas e pesquisadores do ensino de ciências, entre eles, professores da área da educação e de biologia, física e química no ensino superior. Para este trabalho, fez-se um recorte do público para focar nos professores de física, em formação e em exercício, tanto no ensino médio quanto superior, que responderam ao questionário, para destacar as opiniões desse público específico sobre questões envolvendo as relações entre ciência, tecnologia e sociedade e compará-las com as opiniões do público geral entrevistado.

Entre os entrevistados que lecionam ou pretendem lecionar física no ensino médio, 53\% são homens e 47\% são mulheres. Boa parte dessa parcela do público entrevistado ainda está em formação e esse percentual ligeiramente maior entre os homens reflete, em parte, uma gradativa mudança que vem acontecendo em questões de gênero na docência. De acordo com o Censo Escolar de 2017 (BRASIL, 2018), 80\% dos docentes da educação básica eram mulheres naquele ano. Segundo o Perfil do Professor da Educação Básica (CARVALHO, 2018), de 2009 a 2017, a parcela de homens na docência do ensino médio passou de 35,8\% para 40,4\% do total.

Nesta pesquisa de percepção, o predomínio masculino se torna ainda maior entre os entrevistados que lecionam ou pretendem lecionar física no ensino superior: $76 \%$ são homens e $24 \%$ são mulheres. Há uma vasta literatura, no campo de pesquisas sobre questões de gênero, que trata das diferenças na escolha profissional. Em trabalho de revisão bibliográfica, Lima et al. (2017), além de mencionarem estudos sobre homens na docência da educação básica, onde as mulheres são maioria, apontam pesquisas sobre a presença das mulheres em carreiras científicas como a física. 
Tabela 1. Comparação dos gêneros dos professores de física, em formação e em exercício, com os gêneros do universo geral de entrevistados.

\begin{tabular}{|l|c|c|}
\hline & Mulheres & Homens \\
\hline Universo geral de entrevistados1 & $60,3 \%$ & $39,3 \%$ \\
\hline $\begin{array}{l}\text { Entrevistados que lecionam ou pretendem lecio- } \\
\text { nar física no ensino médio }\end{array}$ & $47 \%$ & $53 \%$ \\
\hline $\begin{array}{l}\text { Entrevistados que lecionam ou pretendem lecio- } \\
\text { nar física no ensino superior }\end{array}$ & $24 \%$ & $76 \%$ \\
\hline
\end{tabular}

Fonte: Dados coletados pelo Autor, 2021.

A faixa etária com maior percentual entre os que lecionam ou pretendem lecionar física no ensino médio é a dos entrevistados mais jovens, com até 29 anos: 49,7\%. Como veremos adiante, boa parte desses jovens são estudantes de graduação. Entre os demais professores de física do ensino médio entrevistados, 24,2\% têm entre 30 e 39 anos, 14,6\% têm entre 40 e 49 anos e 11,5\% têm 50 anos ou mais. O predomínio da faixa mais jovem se mantém entre os que lecionam ou pretendem lecionar física no ensino superior: 52\% têm até 29 anos, 26\% têm entre 40 e 49 anos, $12 \%$ têm 50 anos ou mais e $10 \%$ têm entre 30 e 39 anos.

Tabela 2. Comparação das faixas de idade dos professores de física, em formação e em exercício, com as faixas de idade do universo geral de entrevistados

\begin{tabular}{|l|c|c|c|c|}
\hline & $\begin{array}{c}\text { Até } 29 \\
\text { anos }\end{array}$ & $\begin{array}{c}\text { Entre 30 e } \\
39 \text { anos }\end{array}$ & $\begin{array}{c}\text { Entre 40 e } \\
49 \text { anos }\end{array}$ & $\begin{array}{c}50 \text { anos ou } \\
\text { mais }\end{array}$ \\
\hline Universo geral de entrevistados & $33,2 \%$ & $30,6 \%$ & $21,1 \%$ & $15,1 \%$ \\
\hline $\begin{array}{l}\text { Entrevistados que lecionam ou pretendem } \\
\text { lecionar física no ensino médio }\end{array}$ & $49,7 \%$ & $24,2 \%$ & $14,6 \%$ & $11,5 \%$ \\
\hline $\begin{array}{l}\text { Entrevistados que lecionam ou pretendem } \\
\text { lecionar física no ensino superior }\end{array}$ & $52 \%$ & $10 \%$ & $26 \%$ & $12 \%$ \\
\hline
\end{tabular}

Fonte: Dados coletados pelo Autor, 2021.

A maioria dos entrevistados que lecionam ou pretendem lecionar física no ensino médio tem nível de graduação: 32\% são estudantes de licenciatura e 19\% têm graduação completa. Curiosamente, entre os que lecionam ou pretendem lecionar física no ensino superior, $36 \%$ também são estudantes de licenciatura, curso voltado para a formação de professores da educação básica, incluindo cursos técnicos e profissionalizantes. Pode ser que parte desses estudantes também esteja cursando, paralelamente, o bacharelado em física, mas essa questão não estava contemplada no questionário, cujo público alvo, além de professores em exercício na educação básica e de pesquisadores no ensino superior, era de estudantes de licenciaturas. 
Entre os entrevistados que lecionam ou pretendem lecionar física no ensino médio, 23\% têm nível de mestrado, 13\% têm nível de doutorado e 13\% têm nível de especialização. Esse alto índice de escolaridade de praticamente metade dos entrevistados desse grupo difere da realidade geral da docência em física no ensino médio: de acordo com o Resumo Técnico do Censo da Educação Básica 2019 (BRASIL, 2020), apenas 45,8\% dos professores de física do ensino médio têm formação de licenciatura na mesma área da disciplina ministrada. O Perfil do Professor da Educação Básica (CARVALHO, 2018) aponta que em 2017, 23,2\% dos docentes do ensino médio tinham pós-graduação, sendo a maioria em nível de especialização.

Entre os entrevistados na pesquisa de percepção sobre ensino de ciências naturais que lecionam ou pretendem lecionar física no ensino superior, $44 \%$ têm nível de doutorado e $20 \%$ têm nível de mestrado.

Tabela 3. Comparação das escolaridades dos professores de física, em formação e em exercício, com as escolaridades do universo geral de entrevistados.

\begin{tabular}{|l|c|c|c|}
\hline & Universo geral & Física EM & Física ES \\
\hline Cursando graduação & $14,8 \%$ & $32 \%$ & $36 \%$ \\
\hline Graduação completa & $14 \%$ & $19 \%$ & \\
\hline Cursando especialização & $3,3 \%$ & $1 \%$ & \\
\hline Especialização completa & $14,7 \%$ & $12 \%$ & \\
\hline Cursando mestrado & $9,2 \%$ & $15 \%$ & $12 \%$ \\
\hline Mestrado completo & $13,5 \%$ & $8 \%$ & $8 \%$ \\
\hline Cursando doutorado & $11,4 \%$ & $8 \%$ & $8 \%$ \\
\hline Doutorado completo & $19,1 \%$ & $5 \%$ & $36 \%$ \\
\hline
\end{tabular}

Fonte: Dados coletados pelo Autor, 2021.

\section{Opinião dos professores de física}

Ao serem questionados sobre qual deveria ser o foco do ensino de ciências naturais, $68 \%$ dos que lecionam ou pretendem lecionar física no ensino superior e $66,1 \%$ dos que lecionam ou pretendem lecionar física no ensino médio responderam que o foco deveria ser tanto a natureza da ciência, seus processos e produtos quanto questões sociais da vida dos estudantes com alguma relação com ciência e tecnologia. Fazendo um recorte com apenas os estudantes de licenciatura em física, 66,2\% têm essa mesma opinião. Embora os percentuais sejam altos, são relativamente menores do percentual dos que têm a mesma opinião no universo geral de entrevistados $(73,3 \%)$. Essa diferença se reflete nos percentuais dos que consideram que o foco deve ser maior na natureza da ciência ou em questões sociais. 
Tabela 4. Comparação das escolaridades dos professores de física, em formação e em exercício, com as escolaridades do universo geral de entrevistados ${ }^{2}$.

\begin{tabular}{|l|c|c|c|c|}
\hline & Universo & $\begin{array}{c}\text { Licenciatura } \\
\text { em física }\end{array}$ & Física & Física \\
\hline $\begin{array}{l}\text { Tanto a natureza da ciência } \\
\text { quanto questões sociais }\end{array}$ & $73,3 \%$ & $66,2 \%$ & $66,1 \%$ & $68 \%$ \\
\hline $\begin{array}{l}\text { A natureza da ciência ou maior } \\
\text { na natureza da ciência }\end{array}$ & $15,5 \%$ & $16,9 \%$ & $21,8 \%$ & $20 \%$ \\
\hline $\begin{array}{l}\text { Questões sociais ou maior em } \\
\text { questões sociais }\end{array}$ & $10,6 \%$ & $16,9 \%$ & $12,1 \%$ & $10 \%$ \\
\hline
\end{tabular}

Fonte: Dados coletados pelo Autor, 2021.

A maioria dos que lecionam ou pretendem lecionar física no ensino superior (54\%) e dos que lecionam ou pretendem lecionar física no ensino médio $(52,1 \%)$ considera que o ensino de ciências deve privilegiar tanto a formação de novos cientistas quanto a formação dos estudantes para tomadas de decisões como cidadãos. Entre os estudantes de licenciatura em física, 54,9\% têm essa mesma opinião, percentual idêntico ao dos que têm a mesma opinião no universo geral de entrevistados. Há uma diferença considerável nos percentuais dos que consideram que o ensino deve privilegiar mais a formação para tomadas de decisões: essa é a opinião de 14,4\% do total de entrevistados, de $16,9 \%$ dos estudantes de licenciatura em física, de 18,2\% dos que lecionam ou pretendem lecionar física no ensino médio e de $20 \%$ dos que lecionam ou pretendem lecionar física no ensino superior.

Tabela 5. Comparação da opinião dos professores de física, em formação e em exercício, sobre o que o ensino deve privilegiar, com a opinião do universo geral de entrevistados ${ }^{3}$.

\begin{tabular}{|l|c|c|c|c|}
\hline & Universo & $\begin{array}{c}\text { Licenciatura } \\
\text { em física }\end{array}$ & $\begin{array}{c}\text { Física } \\
\text { EM }\end{array}$ & $\begin{array}{c}\text { Física } \\
\text { ES }\end{array}$ \\
\hline $\begin{array}{l}\text { Tanto a formação de cientistas quanto a for- } \\
\text { mação para tomada de decisões }\end{array}$ & $54,9 \%$ & $54,9 \%$ & $52,1 \%$ & $54 \%$ \\
\hline A formação para tomada de decisões & $29,2 \%$ & $23,9 \%$ & $28,5 \%$ & $22 \%$ \\
\hline Mais a formação para tomada de decisões & $14,4 \%$ & $16,9 \%$ & $18,2 \%$ & $20 \%$ \\
\hline
\end{tabular}

Fonte: Dados coletados pelo Autor, 2021.

2 A soma dos percentuais do universo geral de entrevistados e dos professores de física no ensino superior não chega a $100 \%$, porque uma pequena parcela não soube opinar.

3 Não foram incluídos, nesta tabela, os percentuais dos que consideram que o ensino deve privilegiar a formação de novos cientistas ou mais a formação de novos cientistas, por serem muito baixos. 
Aproximadamente $90 \%$ dos estudantes de licenciatura em física e dos professores de física do ensino médio concordam que as intervenções humanas na natureza através da ciência ou da tecnologia não são sempre benéficas e também não são sempre maléficas, mesmo percentual do universo geral de entrevistados. A concordância, nessa questão, chega a 94\% entre os professores de física do ensino superior. As diferenças estão nos percentuais dos que concordam totalmente e dos que concordam parcialmente. Os professores de física do ensino superior são o grupo com maior percentual de concordância total nessa questão.

Tabela 6. Percentuais dos que concordam que as intervenções humanas na natureza através da ciência ou da tecnologia não são sempre benéficas e também não são sempre maléficas.

\begin{tabular}{|l|c|c|c|c|}
\hline & $\begin{array}{c}\text { Universo } \\
\text { geral }\end{array}$ & $\begin{array}{c}\text { Licenciatura } \\
\text { em física }\end{array}$ & $\begin{array}{c}\text { Física } \\
\text { EM }\end{array}$ & $\begin{array}{c}\text { Física } \\
\text { ES }\end{array}$ \\
\hline Concordam totalmente & $65,3 \%$ & $62 \%$ & $59,4 \%$ & $76 \%$ \\
\hline Concordam parcialmente & $25,7 \%$ & $29,6 \%$ & $29,7 \%$ & $18 \%$ \\
\hline
\end{tabular}

Fonte: Dados coletados pelo Autor, 2021.

Também ficou em torno de 90\%, no universo geral de entrevistados, a parcela dos que concordam que as soluções da ciência ou da tecnologia para resolver um determinado problema podem, eventualmente, gerar outro tipo de problema. Os que têm a mesma opinião, entre professores de física dos ensinos médio e superior, chegam a cerca de 94\%; e, entre estudantes de licenciatura em física, 95,8\% têm essa opinião. Novamente, há diferenças consideráveis nos percentuais de concordâncias totais ou parciais. Seria interessante investigar, em um posterior estudo qualitativo com grupos focais de professores de física do ensino médio e de estudantes de licenciatura em física, as razões para o percentual relativamente alto de concordância parcial nessa questão. Novamente, o grupo dos professores de física do ensino superior é o que apresenta o maior percentual de concordância total nessa questão.

Tabela 7. Percentuais dos que concordam que as soluções da ciência ou da tecnologia para resolver um determinado problema podem, eventualmente, gerar outro tipo de problema

\begin{tabular}{|l|c|c|c|c|}
\hline & Universo & $\begin{array}{c}\text { Licenciatura } \\
\text { em física }\end{array}$ & Física & Física \\
& geral & & EM & ES \\
\hline Concordam totalmente & $52,3 \%$ & $52,1 \%$ & $49,1 \%$ & $70 \%$ \\
\hline Concordam parcialmente & $36,9 \%$ & $43,7 \%$ & $45,5 \%$ & $24 \%$ \\
\hline
\end{tabular}

Fonte: Dados coletados pelo Autor, 2021. 
Outra afirmação que obteve a concordância de aproximadamente 90\%, tanto dos professores de física dos ensinos médio e superior quanto do universo geral de entrevistados, é que para participar de um debate sobre questões envolvendo ciência e tecnologia, é preciso considerar os possíveis riscos e benefícios dos avanços científicos e tecnológicos. Entre os estudantes de licenciatura em física, essa é a opinião de 85,9\%. Mais uma vez, há diferenças consideráveis nos percentuais dos que concordam totalmente e dos que concordam parcialmente.

Tabela 8. Percentuais dos que concordam que para participar de um debate sobre questões envolvendo ciência e tecnologia, é preciso considerar os possíveis riscos e benefícios.

\begin{tabular}{|l|c|c|c|c|}
\hline & Universo geral & $\begin{array}{c}\text { Licenciatura } \\
\text { em física }\end{array}$ & $\begin{array}{c}\text { Física } \\
\text { EM }\end{array}$ & Física \\
ES \\
\hline Concordam totalmente & $73,1 \%$ & $56,3 \%$ & $63,6 \%$ & $58 \%$ \\
\hline Concordam parcialmente & $20,5 \%$ & $29,6 \%$ & $27,3 \%$ & $32 \%$ \\
\hline
\end{tabular}

Fonte: Dados coletados pelo Autor, 2021.

Embora a maioria dos professores de física do ensino superior concorde totalmente nessa questão, talvez seja interessante investigar, em posterior estudo de caso com esse público específico, as razões para que não seja tão alta quanto nas questões anteriores a concordância total com a afirmação de que para participar de um debate sobre questões envolvendo ciência é tecnologia, é preciso considerar os possíveis riscos e benefícios dos avanços científicos e tecnológicos. Essa foi a questão que apresentou o maior percentual de concordância total no universo geral de entrevistados e é considerada crucial nas pesquisas sobre abordagens envolvendo as relações entre ciência, tecnologia e sociedade. Silva e Carvalho (2009, p. 136), por exemplo, afirmam que, "de modo geral, a proposta CTS chama a atenção para a necessidade de uma avaliação dos riscos e benefícios associados à aplicação da Ciência e da Tecnologia”.

\section{A alta relevância dos temas socioambientais}

O questionário da pesquisa de percepção sobre ensino de ciências naturais apresentava aos entrevistados uma lista com quatro temas do cânone da ciência e cinco temas socioambientais, para que fosse atribuída a eles uma relevância em uma escala de zero (0) a dez (10), em que zero é nada relevante e dez é extremamente relevante.

Um dos temas do cânone da ciência dessa lista é tradicional no ensino de física: "As três Leis de Newton sobre o comportamento estático e dinâmico dos corpos”. Outro tema do câno- 
ne da ciência, "O Modelo Geocêntrico de Ptolomeu e o Modelo Heliocêntrico de Copérnico", está entre os que são escolhidos para abordagens de ensino de física que abarcam a história da ciência, para contemplar um dos itens da natureza da ciência, o das verdades provisórias e das mudanças de paradigmas.

Campos (2017) mostra que o ensino de conceitos canônicos da física, como os da mecânica ou da termodinâmica, pode ter como ponto de partida um tema gerador ligado à realidade dos alunos. Strieder e Kawamura (2008) também apresentam um tema próximo aos estudantes, a construção de uma usina hidrelétrica na cidade deles, que possibilitou um trabalho interdisciplinar envolvendo física, biologia e geografia. Partindo do ensino transformador proposto por Paulo Freire e de sua associação com a abordagem CTS, esses autores observam que

o conteúdo programático da educação deve ser organizado a partir da realidade vivenciada pelos educandos e da percepção que possuem da mesma. Essa organização está baseada em uma abordagem de temas, os denominados temas geradores, que permitem o estabelecimento de relações entre os homens e o mundo. STRIEDER \& KAWAMURA (2008, p. 3)

Entre os temas socioambientais da lista apresentada na pesquisa de percepção, "Vantagens e desvantagens das diversas fontes de geração de energia" possibilita trabalhos interdisciplinares envolvendo aulas de física, de geografia (abordando, por exemplo, a geopolítica mundial em torno do petróleo) e de biologia (tratando, entre outras coisas, dos biocombustíveis). Outros temas socioambientais que possibilitam trabalhos interdisciplinares são "Energia nuclear e os acidentes de Goiânia, Chernobyl e Fukushima" e "Projeto Manhattan e as bombas atômicas de Hiroshima e Nagazaki”, podendo envolver as disciplinas de física, química e história.

Na pesquisa de percepção sobre ensino de ciências naturais, os professores de física do ensino médio, em exercício e em formação, seguem a tendência do universo geral de entrevistados de dar maior relevância aos temas socioambientais do que aos temas do cânone da ciência, embora todos os temas da lista tenham ficado com uma relevância média consideravelmente alta, acima de 8, para esse grupo.

Os estudantes de licenciatura em física por sua vez, também atribuem maior relevância aos temas socioambientais, mas consideram dois temas do cânone da ciência com relevância média acima de 9: "A Teoria da Evolução e as diferenças entre Lamarck, Darwin e Wallace" e "As três Leis de Newton sobre o comportamento estático e dinâmico dos corpos".

Os que lecionam ou pretendem lecionar física no ensino superior são o único grupo que atribuiu relevância média acima de 9 para quase todos os temas da lista. $\mathrm{O}$ único tema que ficou 
com relevância média abaixo de 9 para esse grupo foi "Projeto Manhattan e as bombas atômicas de Hiroshima e Nagazaki"; ainda assim, também é uma média relativamente alta: 8,88.

Tabela 9. Relevância média atribuída pelos entrevistados a cinco temas socioambientais e quatro temas do cânone da ciência.

\begin{tabular}{|l|c|c|c|c|}
\hline & $\begin{array}{c}\text { Universo } \\
\text { geral }\end{array}$ & $\begin{array}{c}\text { Licenciatura } \\
\text { em física }\end{array}$ & $\begin{array}{c}\text { Física } \\
\text { EM }\end{array}$ & $\begin{array}{c}\text { Física } \\
\text { ES }\end{array}$ \\
\hline $\begin{array}{l}\text { Biodiversidade, desmatamento e preservação } \\
\text { ambiental }\end{array}$ & 9,78 & 9,89 & 9,73 & 9,72 \\
\hline $\begin{array}{l}\text { Efeito estufa, aquecimento global e mudanças } \\
\text { climáticas }\end{array}$ & 9,68 & 9,86 & 9,59 & 9,60 \\
\hline $\begin{array}{l}\text { Vantagens e desvantagens das diversas fontes de } \\
\text { geração de energia }\end{array}$ & 9,67 & 9,73 & 9,73 & 9,70 \\
\hline $\begin{array}{l}\text { Energia nuclear e os acidentes de Goiânia, Cher- } \\
\text { nobyl e Fukushima }\end{array}$ & 9,15 & 9,32 & 9,19 & 9,06 \\
\hline $\begin{array}{l}\text { A Teoria da Evolução e as diferenças entre La- } \\
\text { marck, Darwin e Wallace }\end{array}$ & 8,74 & 9,14 & 8,60 & 9,30 \\
\hline $\begin{array}{l}\text { As três Leis de Newton sobre o comportamento } \\
\text { estático e dinâmico dos corpos }\end{array}$ & 8,74 & 9,25 & 8,90 & 9,40 \\
\hline $\begin{array}{l}\text { Projeto Manhattan e as bombas atômicas de Hi- } \\
\text { roshima e Nagasaki }\end{array}$ & 8,71 & 8,99 & 8,73 & 8,88 \\
\hline $\begin{array}{l}\text { Funções orgânicas e inorgânicas e reações quí- } \\
\text { micas }\end{array}$ & 8,64 & 8,66 & 8,32 & 9,08 \\
\hline $\begin{array}{l}\text { O Modelo Geocêntrico de Ptolomeu e o Modelo } \\
\text { Heliocêntrico de Copérnico }\end{array}$ & 8,41 & 8,92 & 8,65 & 9,06 \\
\hline
\end{tabular}

Fonte: Dados coletados pelo Autor, 2021.

O primeiro dado a ser destacado na tabela acima é a altíssima relevância atribuída pelos estudantes de licenciatura em física aos temas "Biodiversidade, desmatamento e preservação ambiental" e "Efeito estufa, aquecimento global e mudanças climáticas", seguindo a tendência da parcela mais jovem do universo geral de entrevistados. Entre os respondentes com até 29 anos, incluindo os professores de ciências, biologia, física e química, em exercício e em formação, cerca de $90 \%$ atribuíram relevância máxima para esses dois temas. Ambos tratam de questões prioritárias para a juventude de hoje, pois envolvem as perspectivas em relação ao futuro do planeta.

Ao mesmo tempo em que as relevâncias médias atribuídas pelos professores de física dos ensinos médio e superior aos quatro temas socioambientais do topo da lista são muito próximas das relevâncias médias atribuídas pelo universo geral de entrevistados, para os professores de física, o tema "Vantagens e desvantagens das diversas fontes de geração de energia" passa a ocupar o segundo lugar entre os mais relevantes. 
No entanto, é importante observar que, embora o tema "Efeito estufa, aquecimento global e mudanças climáticas" tenha ficado em terceiro lugar na lista dos mais relevantes para os professores de física, a relevância média desse tema ficou acima da de todos os temas do cânone da ciência para os entrevistados desse grupo. Mesmo entre os professores de física do ensino superior, que atribuíram relevância acima de 9,0 para quase todos os temas.

Entre os temas do cânone da ciência, como era de se esperar, os dois mais ligados ao ensino de física, "As três Leis de Newton sobre o comportamento estático e dinâmico dos corpos" e "O Modelo Geocêntrico de Ptolomeu e o Modelo Heliocêntrico de Copérnico" receberam dos estudantes de licenciatura em física e dos professores de física, tanto do ensino médio quanto superior, relevância média acima da atribuída pelo universo geral de entrevistados. No entanto, vale lembrar que tanto os professores de física do ensino superior quanto os estudantes de licenciatura em física atribuíram relevância acima de 9,0 para "A Teoria da Evolução e as diferenças entre Lamarck, Darwin e Wallace".

\section{Considerações Finais}

Os dados desta pesquisa mostram que os pressupostos do ensino CTS já estão bastante consolidados, senão na prática do ensino, pelo menos na percepção dos professores de ciências naturais, incluindo os professores de física, cujas opiniões, como vimos acima, não diferem substancialmente das opiniões do universo geral de entrevistados. Vale lembrar, no entanto, o alto nível de escolaridade do público entrevistado, em comparação com a realidade da docência na educação básica.

Entre as pequenas diferenças de opinião dos professores de física em relação ao universo geral de entrevistados, esse grupo apresenta um percentual maior de entrevistados que consideram que o foco do ensino de ciências naturais deve ser a natureza da ciência ou deve ser maior na natureza da ciência do que em questões sociais. Ao mesmo tempo, o grupo de professores de física também apresenta um percentual maior do que o do universo geral de entrevistados entre os que consideram que o ensino de ciências naturais deve privilegiar mais a formação para tomadas de decisões do que a formação de novos cientistas.

Esta pesquisa de percepção pode gerar desdobramentos futuros, como por exemplo, a investigação das semelhanças e diferenças em propostas de ensino dos grupos majoritários, que defendem um equilíbrio entre natureza da ciência e questões sociais ou entre formação de novos cientistas e formação para tomadas de decisões, e dos grupos minoritários, que dão um peso maior para um desses itens. O que parece já estar claro, pelos resultados apresentados aqui, é que os temas socioambientais, apontados na literatura como potenciais temas geradores para 
o ensino de conceitos científicos, são da mais alta relevância na percepção dos professores de ciências naturais em exercício e em formação.

\section{Rerefências}

BELANÇON, Marcos Paulo. O ensino de física contextualizado ao século XXI. Revista Brasileira de Ensino de Física, v. 39, n. 4, pp. e4001/1-3, 2017.

CAMPOS, Lidiane Benites de. Proposta de abordagem temática com enfoque CTS no ensino de física: produção de energia elétrica. Dissertação (mestrado). Universidade Federal Rural do Rio de Janeiro, Programa de Pós-Graduação em Educação em Ciências e Matemática, 2017.

BRASIL. Instituto Nacional de Estudos e Pesquisas Educacionais Anísio Teixeira (Inep).

Censo da Educação Básica 2019. Resumo Técnico. Brasília, 2020.

BRASIL. Instituto Nacional de Estudos e Pesquisas Educacionais Anísio Teixeira (Inep).

Censo Escolar 2017. Notas Estatísticas. Brasília, 2018.

CARVALHO, Maria Regina Viveiros de. Perfil do professor da educação básica. Brasília, DF: INEP, 2018.

LIMA, Flaviane Izidro Alves de; VOIG, Ana Elisa Gambarti Teixeira; FEIJÓ, Marianne Ramos; CAMARGO, Mário Lázaro; CARDOSO, Hugo Ferrari. A influência da construção de papeis sociais de gênero na escolha profissional. Doxa: Revista Brasileira de Psicologia e Educação, v. 19, n. 1, pp. 33-50, jan./jun. 2017.

SILVA, Luciano Fernandes; CARVALHO, Luiz Marcelo de. Professores de física em formação inicial: o ensino de física, a abordagem CTS e os temas controversos. Investigações em Ensino de Ciências, v. 14, n. 1, pp. 135-148, 2009.

STRIEDER, Roseline; KAWAMURA, Maria Regina. Abordagem CTS no contexto escolar: reflexões a partir de uma intervenção. XI Encontro de Pesquisa em Ensino de Física, Curitiba, 2008.

Recebido: 15 de maio de 2021.

Publicado: 14 de julho de 2021. 